\title{
Caspase cleavage of the nuclear autoantigen LEDGF/p75 abrogates its pro-survival function: implications for autoimmunity in atopic disorders
}

\author{
$X \mathrm{Wu}^{1}$, T Daniels ${ }^{1}, \mathrm{C}$ Molinaro ${ }^{1}$, MB Lilly ${ }^{1,2}$ \\ and CA Casiano*,1,2 \\ ${ }^{1}$ Department of Biochemistry and Microbiology, Center for Molecular Biology \\ and Gene Therapy, Loma Linda University School of Medicine, Loma Linda, CA \\ 92354, USA \\ 2 Department of Medicine, Loma Linda University School of Medicine, Loma \\ Linda, CA 92354, USA \\ * Corresponding author: Carlos A Casiano, Department of Biochemistry and \\ Microbiology, Center for Molecular Biology and Gene Therapy, Loma Linda \\ University School of Medicine, Loma Linda, CA 92354, USA. \\ Tel: (909) 558-1000; Fax: (909)558-4035; E-mail: ccasiano@som.llu.edu
}

Received 11.12.01; revised 28.2.02; accepted 27.3.02

Edited by CJ Thiele

\begin{abstract}
Lens epithelium-derived growth factor p75 (LEDGF/p75) is a nuclear autoantigen in atopic disorders implicated in cellular protection against stress-induced apoptosis. We observed that LEDGF/p75 was cleaved during apoptosis into fragments of 65 and $58 \mathrm{kD}$ generated by caspases-3 and -7 cleaving at three sites: DEVPD ${ }^{30} \downarrow G, D A Q D^{486} \downarrow G$ and WEID ${ }^{85} \downarrow N$. Sequence analysis revealed that the DEVPD ${ }^{30} \downarrow G$ and WEID ${ }^{85} \downarrow N$ sites lie within the highly conserved HATH (homologous to amino terminus of hepatoma-derived growth factor) region, also known as PWWP domain. Alignment of proteins containing this domain failed to reveal conservation of the DEVPD $^{30} \downarrow G$ and WEID ${ }^{85} \downarrow N$ sites, suggesting that the HATH/ PWWP domain of LEDGF/p75 may be specifically targeted by caspases. Overexpression of LEDGF/p75 protected HepG2 cells from serum starvation-induced cell death, whereas expression of the $65 \mathrm{kD}$ fragment failed to protect. The apoptotic cleavage of LEDGF/p75 may contribute to the pathogenesis of atopic disorders by abrogating its prosurvival function and enhancing its immunogenicity.

Cell Death and Differentiation (2002) 9, 915-925. doi:10.1038/ s..cdd. 4401063
\end{abstract}

Keywords: apoptosis; atopy; autoimmunity; caspases; cell survival; LEDGF/p75

Abbreviations: DFS70, dense fine speckled protein of $70 \mathrm{kD}$; HATH, homologous to amino terminal of hepatoma-derived growth factor; HDGF, hepatoma-derived growth factor; HRP, hepatomaderived growth factor related protein; LEDGF, lens epitheliumderived growth factor; PARP, poly(ADP-ribose) polymerase; PSIBLAST, Position Specific Iterated-Basic Local Alignment Search Tool; PWWP, proline-tryptophan-tryptophan-proline; SDS - PAGE, sodium dodecyl sulfate polyacrylamide gel electrophoresis; STS, staurosporine; zVAD-fmk, benzylozycarbonyl-Val-Ala-Asp-fluoromethylketone

\section{Introduction}

The prevalence of atopic disorders, which include atopic dermatitis (AD), asthma, and allergic rhinitis, is rising in Western countries. ${ }^{1} A D$ is a chronic, highly pruritic inflammatory skin disorder that affects approximately 10 to $15 \%$ of the population at some time during childhood and often progresses to asthma and allergic rhinitis in the adult. ${ }^{1}$ While patients with $A D$ often have elevated serum IgE levels and sensitization to environmental allergens, there is evidence that many patients with mild to moderate $A D$ lack clinically relevant sensitivities to food or aeroallergens. ${ }^{2}$ Dysregulation of the immune system, mediated by both extrinsic and intrinsic factors, is believed to play a key role in the pathogenesis of $A D .^{3}$ In $A D$, disease exacerbation is often accompanied by increased $\operatorname{lgG} / \mathrm{lgE}$ antibodies to self-intracellular proteins, implicating autoimmunity as an important pathogenetic factor in this condition. ${ }^{4-10} \mathrm{~A}$ major target of autoantibodies in $A D$ is the dense fine speckles protein of $70 \mathrm{kD}$ (DFS70), distributed in the nucleoplasm during interphase and in condensed chromosomes during mitosis.,5 DFS70 is identical to the transcription co-activator $\mathrm{p} 75^{11}$ and the lens epithelial-derived growth factor (LEDGF) ${ }^{12}$ and is also recognized by autoantibodies in other atopic and inflammatory disorders, including asthma, ${ }^{4}$ interstitial cystitis, ${ }^{4}$ age-related cataract, ${ }^{12}$ and Vogt-Koyanagi-Harada (VKH) disease. ${ }^{13}$ This nuclear autoantigen, better known as LEDGF/p75, is considered a novel survival protein that promotes mammalian cell growth and confers resistance to cell death induced by a wide range of environmental stresses including heat shock, oxidative stress, and serum-starvation. ${ }^{12,14-22}$

While the origin of autoimmunity to intracellular proteins in atopic disorders is unknown, it is presumed that abnormal cell death triggered by environmental allergens or intrinsic factors in the target organs of atopy (skin, eyes, respiratory and gastrointestinal tracts) might facilitate the sustained exposure of potentially immunostimulatory forms of intracellular autoantigens to the immune system. ${ }^{6,23}$ Consistent with this notion is that dysregulated keratinocyte apoptosis contributes to the development of the epidermal lesions associated with $A D .^{24,25}$ Along with Rosen and colleagues, we have shown systematically that many intracellular autoantigens targeted by autoantibodies in systemic autoimmunity undergo proteolytic cleavage during both apoptotic and non-apoptotic cell death. ${ }^{26-31}$ This and other modifications might alter the function of autoantigens, enhance their immunogenicity by exposing cryptic epitopes, 
and stimulate autoantibody responses if they occur under a pro-inflammatory context. ${ }^{31-34}$

In this study we provide evidence that caspase-mediated cleavage of LEDGF/p75 during apoptosis abrogates its prosurvival function. The apoptotic cleavage of LEDGF/p75 may contribute to the pathogenesis of certain atopic and chronic inflammatory disorders by altering its pro-survival function and enhancing its immunogenicity.

\section{Results}

\section{Cleavage of LEDGF/p75 during apoptosis}

During a recent search for novel autoantigens cleaved during cell death, we observed that LEDGF/p75 (called DFS70 in that study) belongs to a subset of intracellular proteins that are cleaved during apoptosis and undergo a second wave of proteolysis as apoptosis progresses into secondary necrosis. ${ }^{28}$ Here we sought to explore the cleavage mechanism of LEDGF/p75 during apoptosis and its biological consequences. Immunoblotting analysis of whole lysates from apoptotic Jurkat, NHEK (normal human epithelium keratinocytes) and Hela cells showed that LEDGF/p75 was cleaved into fragments of approximately 65 and $58 \mathrm{kD}$ (Figure 1A). The $65 \mathrm{kD}$ fragment appeared shortly after the cleavage of poly (ADP-ribose) polymerase (PARP), an early event in apoptosis, whereas the $58 \mathrm{kD}$ fragment appeared later (Figure 1B). LEDGF/p75 cleavage was caspase-dependent since it could be inhibited with the pan-caspase inhibitor benzylozycarbonyl-Val-Ala-Asp-fluoromethylketone (zVADfmk) (Figure 1C).

LEDGF/p75 cleavage did not appear to interfere with its localization to condensed chromatin, ${ }^{4}$ since the protein

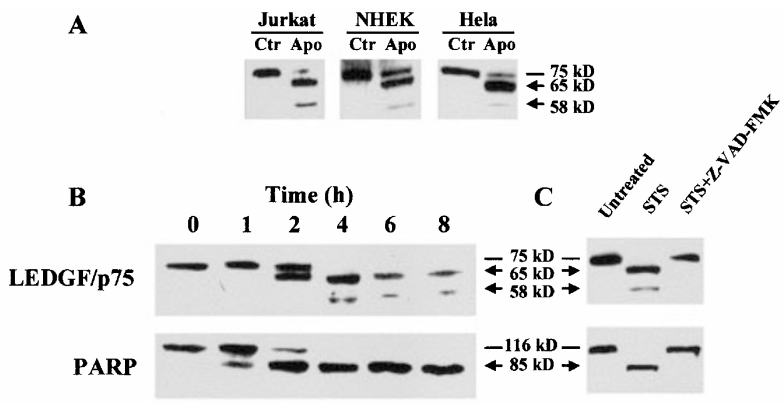

Figure 1 Immunoblots showing the cleavage of LEDGF/p75 in apoptotic cells. (A) LEDGF/p75 was cleaved into a prominent fragment of $65 \mathrm{kD}$ and a minor fragment of $58 \mathrm{kD}$ in Jurkat T cells treated with etoposide for $6 \mathrm{~h}$, and in NHEK and Hela cells treated with staurosporine (STS) for 8 and $6 \mathrm{~h}$, respectively. Ctr, control cells; Apo, apoptotic cells. (B) Kinetics of LEDGF/p75 and PARP cleavage in Jurkat cells undergoing STS-induced apoptosis. (C) Pretreatment of Jurkat cells with zVAD-fmk before induction of apoptosis with STS inhibited the cleavages of LEDGF/p75 and PARP. Proteins were detected with high titer, highly specific human autoantibodies to LEDGF/p75 or PARP. Lines indicate bands corresponding to intact proteins. Arrows indicate bands corresponding to cleavage fragments generated during apoptosis. Approximate molecular weights of the protein bands are shown. Molecular weights were derived using the Bio-Rad Precision Protein Standards (Bio-Rad Laboratories). Blots are representative of at least three independent experiments colocalized with condensed, fragmented chromatin in NHEK undergoing staurosporine-induced apoptosis (Figure 2). Approximately half of the NHEK population displayed nuclear apoptotic morphology after $8 \mathrm{~h}$ of staurosporine treatment, which correlated with the extent of LEDGF/p75 cleavage at this particular time point (Figure 1A). While LEDGF/p75 was almost entirely cleaved into the $65 \mathrm{kD}$ fragment after $12 \mathrm{~h}$ of staurosporine treatment, colocalization of the protein with chromatin in the apoptotic cells was still evident at that time point (data not shown).

\section{LEDGF/p75 is cleaved by caspases-3 and -7 in vitro}

We examined whether caspases-3 and -7 , the main effector caspases in apoptosis, ${ }^{35-38}$ cleave LEDGF/p75 in vitro. In vitro translated LEDGF/p75, fused to T7 protein and $6 \mathrm{x}$ histidine tags, migrated with an apparent molecular weight of $77 \mathrm{kD}$ on SDS-PAGE (Figure 3A, untreated). Incubation of translated LEDGF/p75 with active recombinant caspases-3 and -7 resulted in a major cleavage fragment of approximately $65 \mathrm{kD}$ and a minor fragment of $58 \mathrm{kD}$ (Figure 3A). Caspases$6,-8$, and -9 did not cleave the protein (Figure $3 A$ and data not shown). Incubation of the in vitro-translated LEDGF/p75 with increasing doses of recombinant caspases-3 and -7 showed that the $65 \mathrm{kD}$ fragment was the predominant cleavage product (Figure 3B). The kinetics of in vitro cleavage revealed that the $65 \mathrm{kD}$ fragment appeared first and subsequently underwent cleavage into the $58 \mathrm{kD}$ fragment (Figure $3 \mathrm{C}$ ).

\section{Caspases-3 and -7 cleave LEDGF/p75 at various sites}

Cleavage of in vitro-translated LEDGF/p75 by caspases-3 and -7 into 65 and $58 \mathrm{kD}$ fragments suggested that the cleavage sites recognized by these caspases must be near

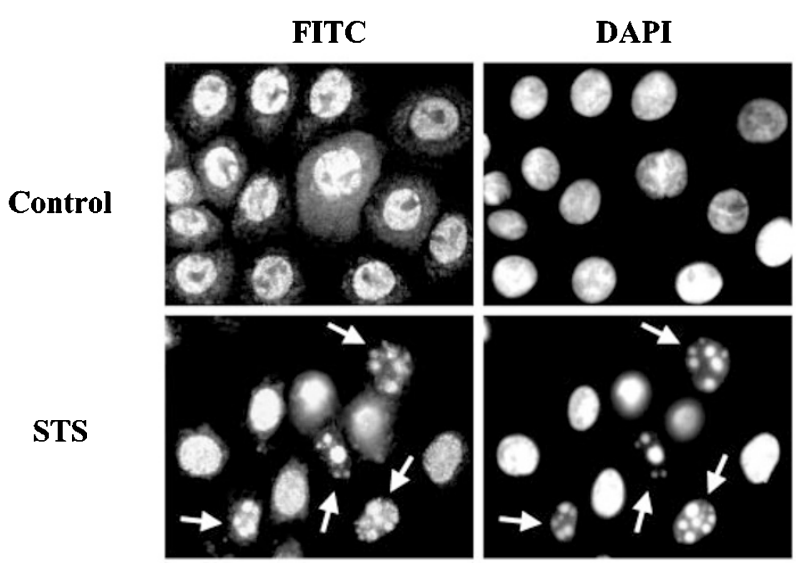

Figure 2 Immunofluorescence pattern of a highly specific anti-LEDGF/p75 human serum in control and STS-treated NHEK. Cells growing in coverslips were treated with STS for $8 \mathrm{~h}$ and then fixed/permeabilized with methanol/ acetone prior to immunostaining. Antibodies to LEDGF/p75 gave a distinctive dense fine speckled staining in nuclei of control NHEK. Corresponding images of nuclei counterstained with 4',6-diamidino-2-phenylindole (DAPI) are shown. Note the colocalization of the LEDGF/p75 and DAPI staining patterns in apoptotic nuclei from staurosporine-treated cells, indicated by arrows 
A

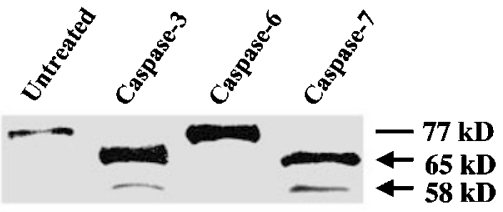

B Concentration (ng/ml)

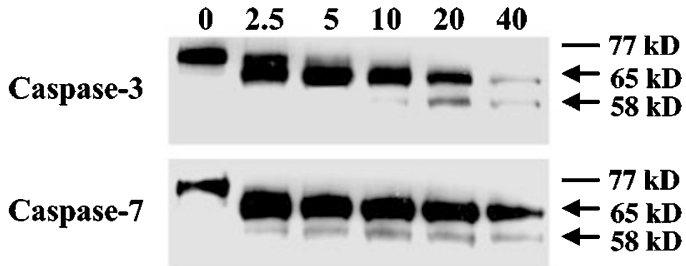

C

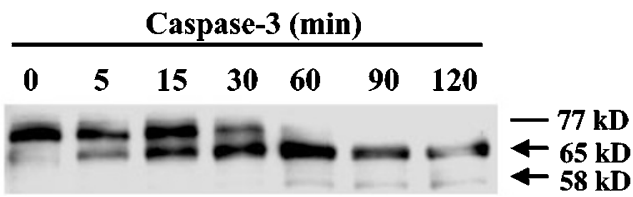

Figure 3 Cleavage of LEDGF/p75 by caspases-3 and -7 in vitro. (A) Biotinylated LEDGF/p75 was generated by in vitro translation and incubated with $20 \mathrm{ng} / \mathrm{ml}$ of recombinant caspases $-3,-6$ and -7 . Cleavage by caspases-3 and -7 generated a prominent fragment of $65 \mathrm{kD}$ and a minor $58 \mathrm{kD}$ fragment, confirming the results in intact cells. (B) Incubation of in vitro translated LEDGF/p75 with increasing doses of recombinant caspases-3 and -7 generated the 65 and $58 \mathrm{kD}$ fragments. (C) Time-dependent progression of in vitro cleavage of translated LEDGF/p75 by $20 \mathrm{ng} / \mathrm{ml}$ of caspase- 3 revealed that generation of the $65 \mathrm{kD}$ fragment precedes that of the $58 \mathrm{kD}$ fragment. Equal amounts $(5 \mu \mathrm{l})$ of translation reactions were loaded to each lane of SDS-PAGE gels. Biotinylated proteins were separated by SDS-PAGE, transferred to nitrocellulose, and detected by enhanced chemiluminescence. Lines indicate bands corresponding to intact proteins. Arrows indicate bands corresponding to cleavage fragments generated during apoptosis. Approximate molecular weights of the protein bands are shown. Molecular weights were derived using the Bio-Rad Precision Protein Standards (Bio-Rad Laboratories). Blots are representative of at least three independent experiments

the $\mathrm{NH}_{2}$ - or $\mathrm{COOH}$-terminal regions. To map these sites, we first searched the LEDGF/p75 amino acid sequence for the presence of the DXXD sequence, which is the consensus cleavage motif recognized by caspases- 3 and -7 . Four such motifs were found near the $\mathrm{NH}_{2}$ - and $\mathrm{COOH}$-terminal regions: $D_{E V P D}{ }^{30} \downarrow G, D N L D^{369} \downarrow V, D^{2} D^{486} \downarrow G$, and $D S K D^{502} \downarrow N$ (Figure 4A). Another potential caspase cleavage motif, WEID ${ }^{85} \downarrow N$ was also identified. While this site does not fit the consensus DXXD motif, we considered it because cleavage after $\mathrm{Asp}^{85}$ would theoretically generate a $\sim 60 \mathrm{kD}$ fragment and effector caspases are known to cleave at nonconventional sites..$^{39,40}$ The predicted molecular weights of the fragments resulting from cleavage at some of these sites are depicted in Figure 4A. To confirm the cleavage sites, we constructed mutant forms of LEDGF/p75 in which Asp residues at position $\mathrm{P} 1$ of the potential caspase cleavage sites were substituted by Ala (Figure 4B). We predicted that these substitutions would block caspase recognition of the sites and inhibit cleavage.
A

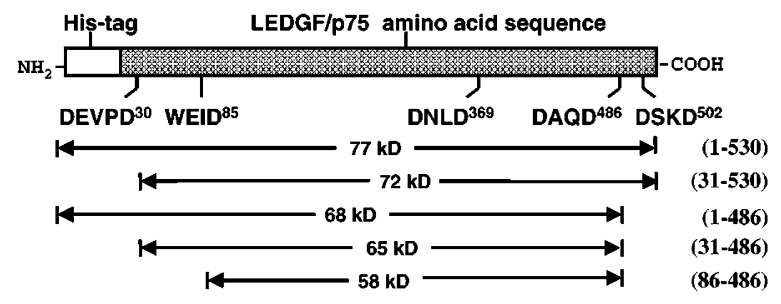

B

$\begin{aligned} \operatorname{DEVPD}^{30} \mathrm{G} & \rightarrow \mathrm{DEVPA}^{30} \mathrm{G} \\ \mathrm{WEID}^{85} \mathrm{~N} & \rightarrow \mathrm{WEIA}^{85} \mathrm{~N} \\ \mathrm{DNLD}^{369} \mathrm{~V} & \rightarrow \mathrm{DNLA}^{369} \mathrm{~V} \\ \mathrm{DAQD}^{486} \mathrm{G} & \rightarrow \mathrm{DAQA}^{486} \mathrm{G} \\ \mathrm{DSKD}^{502} \mathrm{~N} & \rightarrow \mathrm{DSKA}^{502} \mathrm{~N}\end{aligned}$

Figure 4 Schematic representation of putative caspase cleavage sites in LEDGF/p75. (A) The locations of five consensus caspase cleavage motifs likely targeted by caspases, DEVPD ${ }^{30} \downarrow G, D^{2} D^{369} \downarrow V, D A Q D^{486} \downarrow G$, $\mathrm{DSKD}^{502} \downarrow \mathrm{N}$ and WEID ${ }^{85} \downarrow \mathrm{N}$, are shown within the LEDGF/p75 protein. The approximate size of some of the fragments expected from caspase cleavage at those sites are also shown. The numbers of amino acid residues for the intact protein and cleavage fragments are shown in parenthesis. (B) LEDGF/p75 mutants were obtained by substituting the numbered aspartic acid residue on each of the putative caspase cleavage sites into an alanine residue using sitedirected mutagenesis

Incubation of in vitro-translated LEDGF/p75 mutants with caspase- 3 revealed that the mutants containing DNLA ${ }^{369} \downarrow V$ or DSKA ${ }^{502} \downarrow N$ did not block the cleavages but yielded the 65 and $58 \mathrm{kD}$ cleavage fragments (Figure $5 \mathrm{~A}$ ). This suggested that the DNLD ${ }^{369} \downarrow V$ and $D S K D^{502} \downarrow N$ sites are not used preferentially by caspase-3. The mutant containing $D E V P A^{30} \downarrow G$ yielded a fragment that migrated slightly slower than the $65 \mathrm{kD}$ fragment, with an approximately molecular weight of $68 \mathrm{kD}$, consistent with cleavage at the available $D A Q D^{486} \downarrow G$ site (Figure $5 \mathrm{~A}$ ). The mutant containing $D A Q A^{486} \downarrow G$ yielded a predominant fragment that migrated slightly faster than the wild-type, with an approximately molecular weight of $72 \mathrm{kD}$, consistent with cleavage at the available DEVPD ${ }^{30} \downarrow G$ site (Figure $5 A$ ). The mutant containing WEIA ${ }^{85} \downarrow N$ blocked the appearance of the $58 \mathrm{kD}$ fragment but had no effect on the appearance of the $65 \mathrm{kD}$ fragment, consistent with simultaneous cleavage at the available DEVPD ${ }^{30} \downarrow G$ and DAQD ${ }^{486} \downarrow G$ sites (Figure $5 A)$. A double mutant, containing Asp $\rightarrow$ Ala substitutions at both positions $\mathrm{Asp}^{30}$ and $\mathrm{Asp}^{486}$ completely blocked the generation of the 65 and $58 \mathrm{kD}$ fragments (Figure $5 \mathrm{~A}$ ). This confirmed that the $65 \mathrm{kD}$ fragment is generated by simultaneous cleavage at the DEVPD ${ }^{30} \downarrow G$ and $D A Q D^{486} \downarrow G$ sites and serves as a precursor of the $58 \mathrm{kD}$ fragment. These results were reproduced with caspase-7 and using the pcDNAledgf/p75 plasmid (see Materials and Methods) as template for in vitro TNT (data not shown).

To further verify these results, deletion mutants of LEDGF/p75 corresponding to cleavage fragments generated by caspases were amplified by PCR and inserted into a pcDNA3.1+ vector. These mutants were translated in vitro and incubated with recombinant caspase-3. These mutants were designated LEDGF/p75 $\Delta \mathrm{N}$, which lacked 

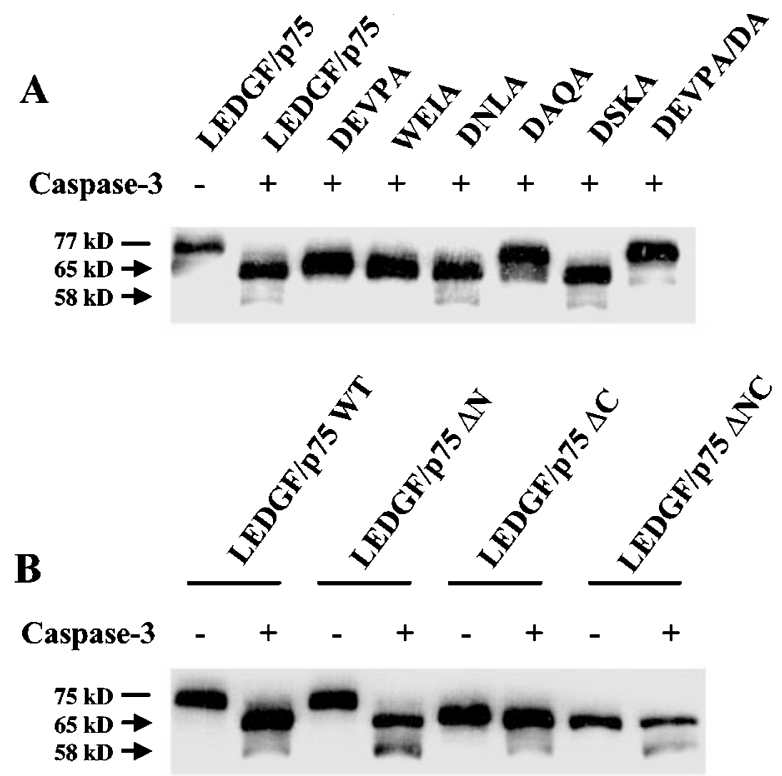

C

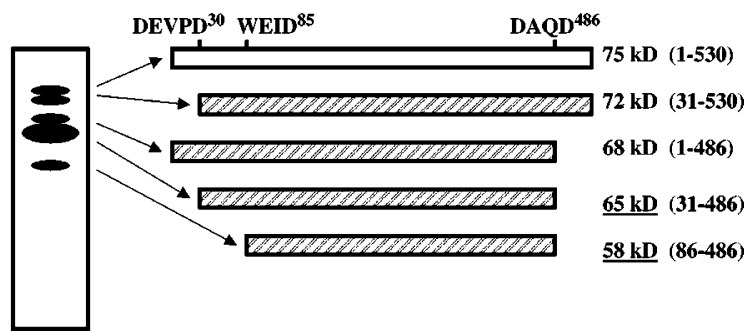

Figure 5 Mapping of the caspase cleavage sites in LEDGF/p75. (A) Mutated versions of LEDGF/p75, as well as (B) truncated versions of the protein corresponding to caspase cleavage fragments, were generated in biotinylated forms by in vitro translation and incubated with $20 \mathrm{ng} / \mathrm{ml}$ of recombinan caspase-3. Biotinylated proteins were separated by SDS-PAGE, transferred to nitrocellulose, and detected by chemiluminescence as indicated in Materials and Methods. Lines indicate bands corresponding to intact proteins. Arrows indicate bands corresponding to cleavage fragments generated during apoptosis. Approximate molecular weights of the protein bands are shown. Molecular weights were derived using the Bio-Rad Precision Protein Standards (Bio-Rad Laboratories). (C) Schematic representation of the cleavage of LEDGF/p75 by caspases-3 and -7 at three different sites: $D_{E V P D}^{30} \downarrow G, W E I D^{85} \downarrow N$, and DAQD ${ }^{486} \downarrow G$. The 65 and $58 \mathrm{kD}$ apoptotic fragments are underlined. Putative fragments not normally observed in apoptotic cells are also depicted. The numbers of amino acid residues for the intact protein and cleavage fragments are shown in parenthesis

residues $1-30$ and corresponded to the fragment generated by cleavage at the DEVPD ${ }^{30} \downarrow G$ site; LEDGF/p75 $\Delta \mathrm{C}$, which lacked residues $487-530$ and corresponded to the fragment generated by cleavage at the $D A Q D^{486} \downarrow G$ site; and LEDGF/p75 $\triangle \mathrm{NC}$, a double mutant lacking residues $1-$ 30 and 487-530 that corresponded to the fragment generated by simultaneous cleavage at the DEVPD ${ }^{30} \downarrow G$ and $D A Q D^{486} \downarrow G$ sites. Figure $5 B$ shows that the migration of the LEDGF/p75 deletion mutants in the presence of caspase- 3 is consistent with cleavage at the sites identified in the experiments described in Figure 5A. LEDGF/p75 $\Delta \mathrm{N}$ migrated near the position of the wild-type LEDGF/p75, which is consistent with the expected migration of a fragment produced by cleavage at the $D E V P D^{30} \downarrow G$ site but not at the $D A Q D^{486} \downarrow G$ site. Incubation of this fragment with caspase-3 produced the 65 and $58 \mathrm{kD}$ fragments generated by cleavage of wild-type LEDGF/p75. LEDGF/ p $75 \Delta \mathrm{C}$ migrated at approximately $68 \mathrm{kD}$, consistent with the expected migration of a fragment produced by cleavage at the DAQD ${ }^{486} \downarrow G$ site but not at the DEVPD ${ }^{30} \downarrow G$ site. As expected, incubation of this fragment with caspase-3 also produced the 65 and $58 \mathrm{kD}$ fragments. LEDGF/p75 $\Delta \mathrm{NC}$ migrated at $65 \mathrm{kD}$, corresponding to the fragment generated by cleavage at both DEVPD ${ }^{30} \downarrow G$ and $D A Q D^{486} \downarrow G$ sites. Incubation of this fragment with caspase-3 did not affect its migration but generated the $58 \mathrm{kD}$ fragment corresponding to further cleavage at the WEID ${ }^{85} \mathrm{~N}$ site. Figure 5C shows a schematic diagram of the LEDGF/p75 fragments that could be generated by caspase cleavage during apoptosis. It should be emphasized, however, that of these putative products only the 65 and $58 \mathrm{kD}$ fragments were observed in apoptotic cells (Figure 1) and during in vitro cleavage of the full-length protein (Figures 3 and $5 A, B)$. Taken together, these results strongly suggest that the $65 \mathrm{kD}$ apoptotic fragment of LEDGF/p75 is generated by simultaneous caspase cleavage at the DEVPD ${ }^{30} \downarrow G$ and $D A Q D^{486} \downarrow G$ sites. This fragment is subsequently cleaved at the WEID ${ }^{85} \downarrow N$ site to yield the $58 \mathrm{kD}$ fragment.

\section{Analysis of LEDGF/p75 sequences containing caspase cleavage sites}

To determine if the identified caspase cleavage sites are conserved in LEDGF/p75 proteins from different species, we compared the LEDGF/p75 sequence with complete and unfinished genomes of mammalian species at www.tigr.org. Figure $6 \mathrm{~A}$ shows that the DEVPD ${ }^{30} \downarrow G$ and WEID ${ }^{85} \downarrow N$ sites are conserved in LEDGF/p75 proteins from human, mouse, and rat. However, the DAQD ${ }^{486} \downarrow G$ site is conserved in bovine, but not in mouse LEDGF/p75 (the rat $\mathrm{COOH}$-terminal sequence was not available). This suggests that $D A Q D^{486} \downarrow G$ may not be critical for the apoptotic cleavage of LEDGF/p75 in murine cells.

Effector caspases often cleave at sites adjacent to or within functionally important domains, activating or inactivating their target substrates. ${ }^{36-38}$ Although very little is known about functional domains within the LEDGF/p75 sequence, we investigated whether the DEVPD ${ }^{30} \downarrow G$, WEID ${ }^{85} \downarrow N$, and $D A Q D^{486} \downarrow G$ sites are located within regions or domains that could be associated with the reported survival and growth factor activities of this protein. ${ }^{12,14-22}$ Analysis of the LEDGF/p75 amino acid sequence against the ProDom database yielded a clearly defined domain (residues 6-96) that corresponded to the highly conserved HATH region, previously identified in this protein and some members of the hepatoma-derived growth factor (HDGF) family. ${ }^{12,41}$ This region is also called the PWWP domain because of the presence of a highly conserved proline-tryptophan-tryptophan-proline motif. ${ }^{41} \mathrm{~A}$ PSI-BLAST search against residues 1-127 yielded 114 mammalian proteins with a HATH/PWWP domain. Proteins containing this domain included, in addition to members of the HDGF family, DNA mismatch repair proteins, DNA- 


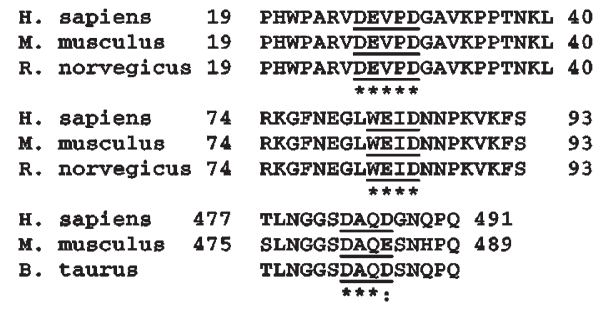

\section{B}

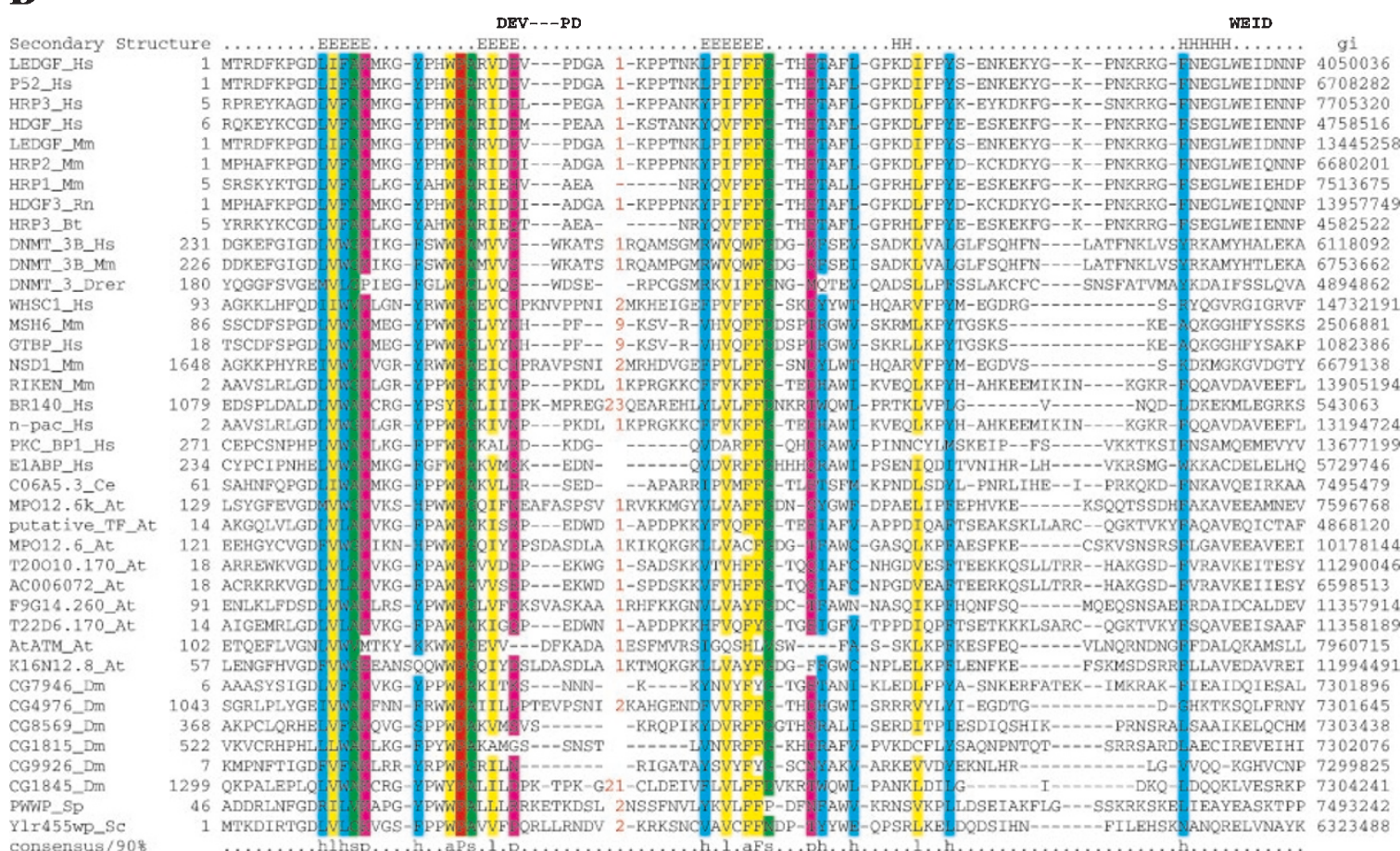

Figure 6 The DEVPD ${ }^{30} \downarrow G$ and WEID ${ }^{85} \downarrow N$ sites are conserved in LEDGF/p75 proteins from different mammalian species and are located within the highly conserved HATH/PWWP domain. (A) Alignment of LEDGF/p75 from different species using CLUSTAL X. The three identified caspase cleavage sites and their flanking regions are shown. The LEDGF/p75 sequences from $R$. norvegicus and $B$. taurus were obtained by searching the unfinished genome databases available at www.tigr.org. (B) A multiple alignment of representative HATH/PWWP domains was constructed by parsing PSI-BLAST-generated highest-scoring pairs of sequence segments and realigning them with CLUSTAL X followed by manual corrections. The predicted consensus secondary structure, determined with the PSIPRED V2.1 and PHDsec programs, with $\mathrm{E}$ indicating a $\beta$-strand and $\mathrm{H}$ an $\alpha$-helix, is shown above the alignment. Upper case denotes a strong prediction provided by both programs. The positions of the DEVPD ${ }^{30} \downarrow \mathrm{G}$ and WEID ${ }^{85} \downarrow \mathrm{N}$ sites in LEDGF/p75 are also shown. The $90 \%$ consensus shown below the alignment was derived using the following amino acid classes: polar (p: KRHEDQNST) shaded purple; hydrophobic (h: ALICVMYFW), shaded cyan; aliphatic (I: LIV) and aromatic (a: YFW) both shaded yellow; and small (s: ACDGNPSTV) shaded green. The limit of the HATH/PWWP domains are indicated by the position numbers on the left side. The GenBank identifiers are indicated on the right side. Long inserts in the alignment are replaced by red-colored numbers. Sequences are denoted by their gene name followed by the species abbreviation: At, Arabidopsis thaliana; Bt, Bos taurus; Ce, Caenorhabditis elegans; Dm, Drosophila melanogaster; Hs, Homo sapiens; Mm, Mus musculus; Rn, Rattus norvegicus; Sc, Saccaromyces cerevisiae; Sp, Schizosaccharomyces pombe

methyl transferases, transcription coactivators, and regulatory proteins that are disrupted by chromosomal translocations in myeloid leukemias (for examples see Figure 6B). In the LEDGF/p75 sequence, the DEVPD ${ }^{30} \downarrow G$ and WEID ${ }^{85} \downarrow N$ cleavage sites are located within the HATH/PWWP domain, with DEVPD ${ }^{30} \downarrow G$ immediately following the conserved PWWP motif (Figure 6). These cleavage sites are not conserved in other HATH/PWWP-containing proteins (except in $\mathrm{p52}$, an alternative splicing product of LEDGFp75.) ${ }^{11,42}$. However, other potential caspase clea- vage sequences may exist in this domain. For example, mouse HRP2 (HDGF-related protein 2) and rat HDGF3 (equivalent to HRP2) have a DIAD sequence after the PWWP motif (Figure 6B).

A PSI-BLAST search against the LEDGF/p75 $\mathrm{COOH}$ terminus (residues $346-530$ ) revealed moderate sequence conservation upstream the DAQD ${ }^{486} \downarrow G$ site in several members of the HDGF family, including human and mouse HRP2 and rat HRP3 (data not shown). The DAQD ${ }^{486} \downarrow G$ site was not conserved in any of these proteins. 


\section{LEDGF/p75 apoptotic fragments have reduced pro-survival functions}

To study whether the apoptotic cleavage of LEDGF/p75 affects its pro-survival function, we generated stably transfected HepG2 cell lines expressing either LEDGF/p75 or its deletion mutants corresponding to caspase-generated fragments. HepG2 cells were chosen for these studies because they expressed relatively lower levels of endogenous LEDGF/p75 than other cell lines examined by immunoblotting (data not shown), and could be used to test the ability of this protein to confer protection against serum starvationinduced cell death. The expression of LEDGF/p75 and its deletion mutants LEDGF/p75 $\Delta$ NC and LEDGF/p75 $\Delta$ C (see above) in stably transfected HepG2 cells was confirmed by immunoblotting (Figure 7A). Cells stably transfected with pcDNA3.1+ vector alone had similar expression levels of LEDGF/p75 as untransfected HepG2 cells, while the protein was overexpressed in cells transfected with plasmid encoding the wild-type protein (Figure 7A). As expected, HepG2 cells stably expressing the LEDGF/p $75 \Delta \mathrm{C}$ and

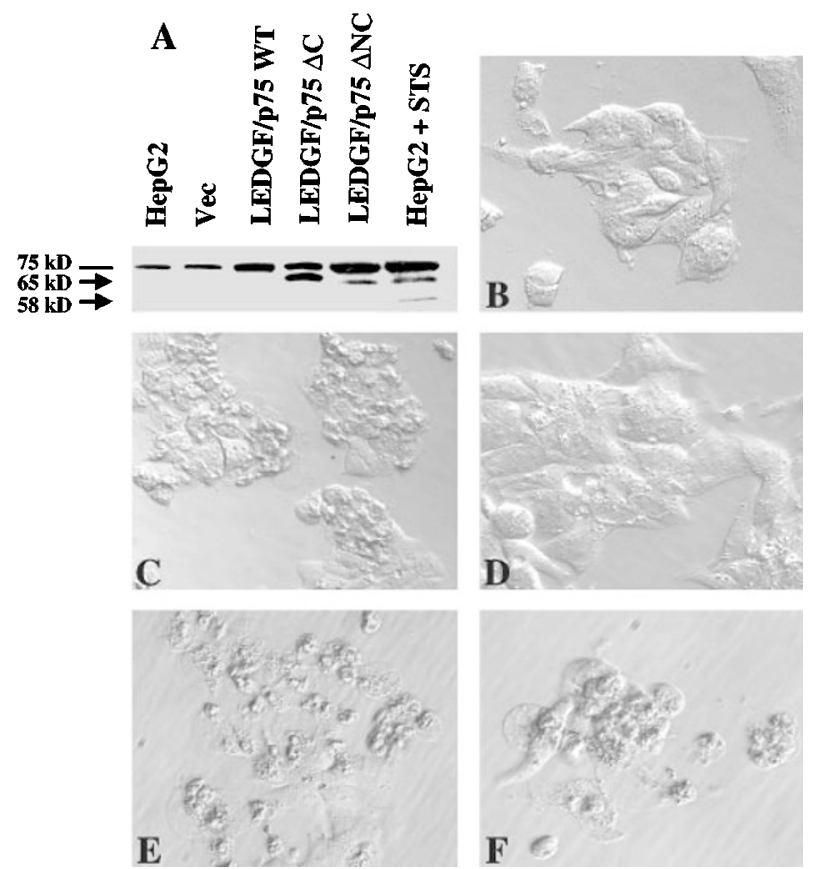

Figure 7 (A) Expression of wild-type (WT) and truncated versions of LEDGF/ p75 $(\Delta)$ corresponding to caspase-generated fragments in stably transfected HepG2 cells, as detected in immunoblots probed with autoantibodies to LEDGF/p75. HepG2 cells treated with $2 \mu \mathrm{M}$ STS for $24 \mathrm{~h}$ served as apoptotic control. Untransfected cells (HepG2) and cells transfected with vector only (Vec) are also shown as negative controls. (B) Morphology of untransfected HepG2 cells growing in complete medium supplemented with $10 \%$ fetal bovine serum (FBS). HepG2 cell clones stably transfected with vector only (C), LEDGF/p75WT (D), LEDGF/p75 $\Delta$ C (E), or LEDGF/p75 under serum free conditions for $96 \mathrm{~h}$. Extensive cell death can be observed in cells transfected with vector only, LEDGF/p75 $\Delta$ C and LEDGF/p75 $\Delta$ NC (C, E and $\mathbf{F}$, respectively) whereas cells stably transfected with LEDGF/p75 WT (D) displayed a morphology identical to that of untransfected control cells (B). Images were acquired at $\times 400$ magnification using an inverted Olympus IX70 microscope equipped with Hoffman modulation contrast
LEDGF/p75 $\triangle \mathrm{NC}$ mutants showed immunoreactive fragments of approximately 68 and $65 \mathrm{kD}$, respectively, in immunoblots (Figure 7A). The $65 \mathrm{kD}$ fragment expressed in HepG2-LEDGF/p75 $\triangle N C$ migrated at the same position as the larger fragment generated during STS-induced HepG2 apoptosis (Figure 7A). The expression level of LEDGF/ p75 $\Delta \mathrm{NC}$ was relatively low and its visualization in immunoblots required loading more cellular protein in the gels. Only a few clones expressing LEDGF/p75 $\triangle \mathrm{NC}$ were obtained, all of which expressed low levels of the mutant protein. This suggested that this mutant might be toxic to cells when expressed at high levels and that only cells expressing low levels were able to survive. Several attempts to generate HepG2 cells stably expressing LEDGF/p $75 \Delta \mathrm{N}$ were unsuccessful, suggesting that expression of this deletion mutant may be lethal.

The ability of LEDGF/p75 and its deletion mutants to protect HepG2 cells against serum starvation-induced death was examined. Figure $7 \mathrm{C}-\mathrm{F}$ shows that while cells transfected with vector alone underwent serum starvationinduced death (Figure 7C), cells transfected with LEDGF/ p75WT (Figure 7D) showed a normal morphology, comparable to that of untransfected HepG2 cells grown in the presence of $10 \%$ FBS (Figure 7B). Expression of the deletion mutants LEDGF/p75 $\Delta$ C (Figure 7E) and LEDGF/p75 $\triangle$ NC (Figure 7F) could not suppress serum starvation-induced cell death. To confirm these results, we examined the survival of the different stably transfected cell lines under serum-free conditions. Overexpression of wild-type LEDGF/p75 significantly protected against cell death, as compared with the survival of the HepG2-Vec clone (Figure $8 \mathrm{~A} ; P<0.001$ ). However, the individual expression of the LEDGF/p75 $\Delta C$ and LEDGF/p75 $\Delta$ NC mutants had no protective function against serum starvation-induced cell death (Figure $8 \mathrm{~A}$ ). While there was no significant difference between the survival of HepG2-Vec and HepG2-LEDGF/p75 $\Delta \mathrm{C}$ clones, expression of the LEDGF/p75 $\Delta$ NC mutant significantly enhanced cell death, when compared with the survival of HepG2-Vec (Figure 8 A; $P<0.001$.

To test whether expression of the deletion mutants affected cell proliferation, the stably transfected cell lines were grown in the presence of $10 \%$ FBS for 24 and $48 \mathrm{~h}$, followed by measurement of relative cell number. After $48 \mathrm{~h}$, cell proliferation was significantly higher in HepG2 clones overexpressing LEDGF/p75WT, as compared with the proliferation of HepG2-Vec (Figure 8B; $P<0.05$ ). Cells expressing LEDGF/p75 $\Delta$ NC showed significantly lower cell proliferation when compared with HepG2-Vec (Figure 8B; $P<0.005)$. There was no significant difference between the relative cell number of HepG2-Vec and HepG2-LEDGF/ p75 $\Delta$ C clones.

All these results were confirmed using at least two different stably transfected clones for each construct. The relevant finding in these experiments is that while overexpression of LEDGF/p75 protects against serum starvation-induced cell death, removal of sequences near its $\mathrm{NH}_{2}-$ and $\mathrm{COOH}$-terminal regions by caspases during apoptosis appeared to abrogate its pro-survival and growth factor functions. 
A

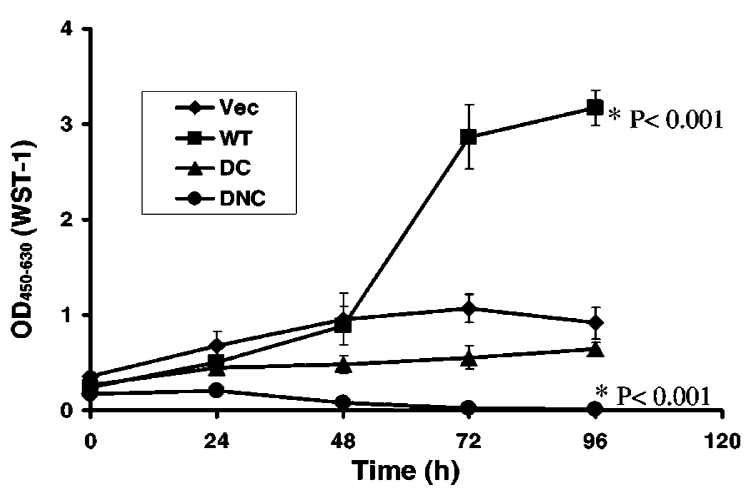

B

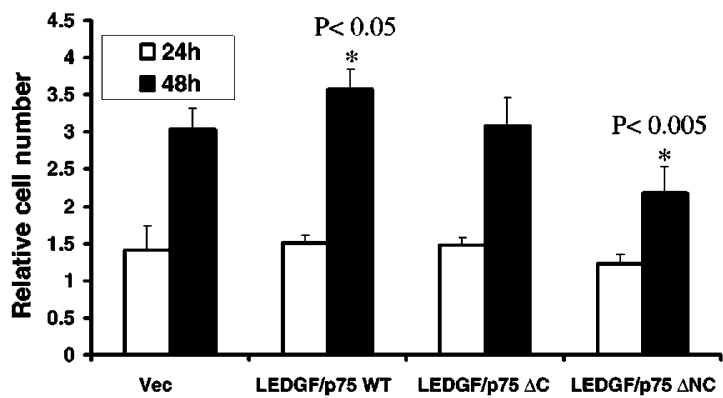

Figure 8 Overexpression of caspase cleavage fragments abolishes the prosurvival activity of LEDGF/p75 and partially inhibits HepG2 cell proliferation. (A) Cell viability of HepG2 cell clones expressing wild-type (WT) and truncated versions of LEDGF/p75 corresponding to caspase-generated fragments. Stably transfected HepG2 cell clones were seeded in 96-well microtiter plates $\left(1.5 \times 10^{4}\right.$ cells/well) 1 day before exposing them to serum free conditions for $96 \mathrm{~h}$. At indicated times, cell viability was determined using the WST-1 assay. The error bars represent means \pm S.D. of six independent experiments conducted in triplicates. (B) Proliferation of HepG2 cell clones expressing wildtype and truncated versions of LEDGF/p75 corresponding to caspasegenerated fragments. Stably transfected HepG2 cell clones were grown in complete medium supplemented with $10 \%$ fetal bovine serum (FBS) for 24 and $48 \mathrm{~h}$. Cell proliferation was measured by WST-1 assay. The relative cell number 1.0 is defined as the cell number of each clone at $0 \mathrm{~h}$. The error bars represent means \pm S.D. of two independent experiments conducted in triplicates. Stars indicate statistical significance ( $P$ values shown) as determined by Student's $t$-test (two-tailed)

\section{Discussion}

\section{Functional implications of the apoptotic cleavage of LEDGF/p75}

Elucidating the mechanisms that maintain the delicate balance between cell death and survival is essential for understanding the pathophysiology of a wide variety of human diseases. These mechanisms include the inactivation of prosurvival proteins, or their conversion into death effectors, during apoptosis by caspases cleaving at or near functionally important domains. ${ }^{43-46}$ The atopy-associated autoantigen LEDGF/p75 is a novel survival protein whose cleavage during apoptosis, along with other substrates, may ensure that the cellular pro-survival machinery does not antagonize the cell death process.

Here we present the first evidence that LEDGF/p75 is cleaved by caspases-3 and -7 during apoptosis and that this cleavage abrogates its pro-survival function. Our data indicates that abrogation of LEDGF/p75 pro-survival activity during apoptosis is dependent on the caspase-mediated removal of amino acid sequences near the $\mathrm{NH}_{2}-$ and $\mathrm{COOH}$-terminal regions by simultaneous cleavage at the $D V_{P D}{ }^{30} \downarrow G$ and $D A Q D^{486} \downarrow G$ sites. Interestingly, the $D E P^{30} \downarrow G$ site was found to be located within the $\mathrm{HATH} / \mathrm{PWWP}$ domain. While the function of this domain is still undefined, it was speculated that it could be involved in protein-protein interactions influencing chromatin remodeling and thereby facilitating fine-tuning of transcription processes. $^{41}$ Our sequence homology search using PSIBLAST indicated that the HATH/PWWP domain is present in at least 114 other eukaryotic proteins and that consensus caspase cleavage sites are not frequently present in this domain. This indicated that LEDGF/p75 may belong to a subset of cellular proteins whose HATH/PWWP domain is specifically targeted for cleavage during apoptosis.

Our results showed that cells stably expressing a deletion mutant corresponding to the $65 \mathrm{kD}$ apoptotic fragment of LEDGF/p75 (called LEDGF/p75 $\Delta \mathrm{NC}$ ) exhibited lower survival and proliferation than cells transfected with vector alone or expressing a fragment corresponding to single cleavage at the $D A D^{486} \downarrow G$ site (LEDGF/p75 $\Delta \mathrm{C}$ ). These negative effects on cell growth and survival occurred in spite of the expression of low amounts of LEDGF/ $\mathrm{p} 75 \Delta \mathrm{NC}$ and the presence of endogenous LEDGF/p75 in the HepG2 cells. This suggested that preserving the integrity of the HATH/PWWP domain might be important for the pro-survival function of LEDGF/p75 and that its $65 \mathrm{kD}$ apoptotic cleavage fragment may act as a dominant negative polypeptide that enhances cell death. Experiments are currently being conducted in our laboratory to confirm this dominant negative effect in various cell types.

The dominant negative effect of LEDGF/p75 $\Delta \mathrm{NC}$ on HepG2 cell survival suggests that the $65 \mathrm{kD}$ cleavage fragment of LEDGF/p75 may acquire a novel pro-apoptotic function during cell death. This would be consistent with previous reports indicating that caspase cleavage of certain survival proteins, such as Bcl-2, Bcl- $x_{L}$, and $A k t / P k B$, converts them into cell death effector proteins. ${ }^{44-46}$ Various scenarios could be envisioned to explain the pro-apoptotic activity of LEDGF/p75 NNC. For instance, LEDGF/p75 $\Delta \mathrm{NC}$ may compete with its full-length anti-apoptotic counterpart for DNA binding, or form aberrant complexes with this and other proteins, resulting in blockade of transcription coactivation functions that might be essential for cell survival. There is evidence that the expression of full-length LEDGF/ p75 increases in cells subjected to environmental stresses, including thermal and oxidative stress, and that the protein confers protection against these stresses by upregulating the expression of stress-related, anti-apoptotic proteins such as heat shock protein 27 (HSP27), $\alpha \mathrm{B}$-crystallin, and AOP2. ${ }^{12,14-22}$ This upregulation is presumed to be mediated by binding of LEDGF/p75 to heat shock element (HSE) and stress-related regulatory elements (STRE) located in the promoters of stress-related genes. ${ }^{15}$ While the ability of LEDGF/p75 $\Delta \mathrm{NC}$ to bind to promoter regions of stress related genes remains to be determined, sequence analysis using the BLOCKS program showed that there is a 
consensus AT-hook DNA binding motif (PRGRP; residues 194-198) that is retained in this cleavage fragment. The presence of this motif facilitates the binding of transcription co-activators, such as high mobility group (HMG) proteins, to the minor groove of short stretches of AT-rich DNA sequences and is involved in the transcription regulation of genes containing, or in close proximity to, these sequences. ${ }^{47}$ Thus, retention of the AT-hook motif predicts that LEDGF/p $75 \Delta N C$ may still bind to DNA sequences, which would be consistent with the colocalization of the protein with fragmented chromatin in apoptotic keratinocytes. It is not clear, however, whether binding of this cleavage fragment to DNA may still promote the expression of pro-survival genes. It can not be ruled out that LEDGF/ p75 $\triangle \mathrm{NC}$ may acquire new transcription coactivator functions that promote the expression of pro-apoptotic genes. Alternatively, this cleavage fragment may have a cell deathinducing effect that is independent of its binding to DNA and transcription co-activator functions. This effect might be mediated by direct interaction with key elements of the apoptotic machinery, such as caspases, mitochondria, or inhibitors of apoptosis proteins (IAPs), via mechanisms yet to be defined.

The reduced pro-survival activity associated with expression of the $\Delta \mathrm{C}$ fragment also implicated the $\mathrm{COOH}$ terminus of LEDGF/p75 in this function. Sequence homology analysis of the $\mathrm{COOH}$-terminus of LEDGF/p75 using PSI-BLAST only retrieved a few HDGF-related proteins (HRPs) and indicated that the region corresponding to residues 338-420 has several clusters of amino acids that are conserved among these proteins and might be part of a functional domain (data not shown). However, the lack of information on structure-function relationships within HRPs makes it difficult to ascertain a specific function to this region. It is possible that LEDGF/p75 and the HRPs may overlap in some functional activities because they share both a HATH/PWWP domain and moderate homology in the $\mathrm{COOH}$-terminus.

\section{Implications of LEDGF/p75 apoptotic cleavage for atopy-associated autoimmunity}

Autoimmunity to intracellular proteins has been recently identified as an important factor in the pathogenesis of atopic disorders, in particular AD. ${ }^{4-10}$ LEDGF/p75 has been identified as a prominent autoantigen (called DFS70) associated with atopy since $30 \%$ of patients with $A D$ and $16 \%$ of patients with asthma were found to produce IgG and IgE autoantibodies that reacted with this protein in immunoblots. ${ }^{4,5}$ The factors leading to autoimmunity to intracellular proteins in $A D$ are not clear, although various scenarios could be invoked to explain this phenomenon. For instance, immune responses directed to environmental allergens may spread to intracellular autoantigens that share structural similarities with these allergens, thus triggering an autoantibody response that is subsequently maintained by the human autoantigens. This molecular mimicry scenario is supported by structural similarities between some environmental allergens and intracellular autoantigens targeted in AD. ${ }^{6}$
A more likely scenario is that tissue damage and aberrant cell death triggered by environmental allergens or intrinsic factors in the target organs of atopy (skin, eyes, respiratory tract, and gastrointestinal tract) could contribute to the release and exposure to the immune system of intracellular antigens. $^{6,23}$ Apoptotic cells are considered reservoirs of potentially immunostimulatory forms of intracellular antigens. ${ }^{31-34}$ Massive apoptosis or defective clearance of apoptotic cells may lead to the accumulation of cells in late apoptotic stages or secondary necrosis, leading to the release of potentially harmful intracellular contents, such as proteases and pro-inflammatory signals, that could damage the surrounding tissue and provoke an inflammatory response. ${ }^{28,33,34,48-52}$ Under a pro-inflammatory environment, modified forms of intracellular antigens (e.g. produced by proteolysis) could be processed and presented by mature dendritic cells (DC) to circulating autoreactive $\mathrm{T}$ cells, thus triggering autoantibody responses.

Aberrant cell death, LEDGF/p75 inactivation by caspases, and autoimmunity to this protein could be interrelated events that might play an important role in the pathogenesis of AD. For instance, massive keratinocyte apoptosis may be induced in AD patients by proinflammatory lymphocytes activated by environmental allergens or other factors. This would be consistent with reports that dysregulated keratinocyte apoptosis induced by activated skin-infiltrating T-cells is a key pathogenic event in the skin lesions associated with $A D .^{23-25}$ If not cleared swiftly by phagocytic cells, a number of apoptotic keratinocytes would undergo secondary necrosis, further enhancing the pro-inflammatory environment. ${ }^{28,33,34,48-50}$ In this environment, mature DC may process and present LEDGF/p75, its apoptotic fragments, and other modified proteins to autoreactive lymphocytes that have escaped deletion, leading to autoimmunity to these proteins. Keratinocyte apoptosis may also be amplified by the $65 \mathrm{kD}$ apoptotic cleavage fragment of LEDGF/p75, which could function as a dominant negative protein that, if released from dying cells into the extracellular environment, might inhibit the survival and proliferation of neighboring cells. In an alternative scenario, anti-LEDGF/p75 autoantibodies may enhance loss of keratinocyte survival by binding to secreted intact LEDGF/p75, thus preventing its uptake by viable keratinocytes. There is evidence that LEDGF/p75 acts as a growth factor that can be secreted by cultured COS7 cells and stimulate the proliferation of neighboring cells that uptake the protein. ${ }^{12}$ Addition of recombinant LEDGF/p75 to the medium of cultured lens cells has been shown to protect against stress-induced cell death. ${ }^{16,18}$ Moreover, deprivation of cultured lens epithelium cells (LEC) of LEDGF/p75 with anti-LEDGF/p75 antibodies was demonstrated to induce LEC death. ${ }^{53}$ Similar mechanisms could also underlie other conditions associated with autoimmunity to LEDGF/p75, such as asthma, age-related cataract, interstitial cystitis, and $\mathrm{VKH}$.

In conclusion, we provide evidence that LEDGF/p75, a nuclear autoantigen associated with certain atopic disorders and other chronic inflammatory conditions, is cleaved by effector caspases during apoptosis in a manner that abrogates its pro-survival function. We propose that the 
apoptotic cleavage of LEDGF/p75 may contribute to the pathogenesis of these disorders by altering its pro-survival functions and enhancing its immunogenicity.

\section{Materials and Methods}

\section{Cell culture and induction of apoptosis}

Normal human epidermal keratinocytes, NHEK (Clonetics/BioWhittaker), Jurkat and Hela cells (American Type Culture Collection) were cultured according to the suppliers' instructions. Apoptosis was induced in actively growing Jurkat cells with $150 \mu \mathrm{M}$ etoposide (Sigma) or $1 \mu \mathrm{M}$ staurosporine (STS; Alexis). Apoptosis was induced in Hela cells and NHEK with $2 \mu \mathrm{M}$ STS. In some experiments, cells were pre-incubated with the pan-caspase inhibitor zVAD-fmk (Enzyme Systems) for 30 min before induction of apoptosis.

\section{Electrophoresis and immunoblotting of cell lysates}

Total cell lysates were prepared as described previously. ${ }^{28}$ Protein concentrations in lysates were determined by the Protein DC Assay Kit (Bio-Rad) to ensure equal loading of proteins per lane in SDS polyacrylamide gels (Ready Gels, Bio-Rad). Electrophoresis and immunoblotting procedures were performed as described previously. ${ }^{28}$

\section{Immunofluorescence microscopy}

NHEK grown on coverslips were washed with phosphate buffered saline (PBS), fixed and permeabilized in methanol/acetone $(3: 1 \mathrm{v} / \mathrm{v})$, and stained with a highly specific human anti-LEDGF/p75 serum. ${ }^{4}$ FITC-conjugated goat anti-human IgG antibody (Caltag Laboratories) was used as secondary detecting reagent. Cells were counterstained with 4',6-diamidino-2-phenylindole (DAPI; Sigma) for DNA visualization. Labeled cells were examined under a fluorescence microscope.

\section{Site directed mutagenesis}

Site-directed mutagenesis of potential caspase cleavage sites within LEDGF/p75 was done by multiple rounds of polymerase chain reaction (PCR) using a pET28a-dfs70 plasmid containing the full-length LEDGF/p75 cDNA (residues 1-530) under the control of a T7 promoter, ${ }^{4}$ following the instructions for the QuikChange ${ }^{(i x}$ sitedirected mutagenesis kit (Stratagene). LEDGF/p75 mutants were constructed to substitute aspartic acid residues in putative caspase cleavage sites by alanine residues. The point mutations generated were $\mathrm{Asp}^{30} \rightarrow \mathrm{Ala}^{30}, \mathrm{Asp}^{85} \rightarrow \mathrm{Ala}^{85}, \mathrm{Asp}^{369} \rightarrow \mathrm{Ala}^{369}, \mathrm{Asp}^{486} \rightarrow \mathrm{Ala}^{486}$ and $\mathrm{Asp}^{502} \rightarrow \mathrm{Ala}^{502}$. Primers used to generate these mutations were: DEVPD $^{30}$ forward ( $5^{\prime}$-GACGAAGTTCCTGCTGGAGCTGTAAAGC- $3^{\prime}$ ); DEVPD ${ }^{30}$ backward (5'-GC-TTTACAGCTCCAGCAGGAACTTCGTC$\left.3^{\prime}\right)$; WEID ${ }^{85}$ forward (5'-GGTTTATGGGAGATAGCGAACAATCCAAAAGTG-3'); WEID ${ }^{85}$ backward (5'-CACTTTTGGATTGTTCGCTATCTCCCATAAACC-3'); DNLD ${ }^{369}$ forward (5'-CACTCAAAATTGATAACCTTGCCGTGAACAGATGC-3'); DNLD ${ }^{369}$ backward (5'GCATCTGTTCACGGCAAGGTTATCAATTTTGAGTG-3'); DAQD ${ }^{486}$ forward (5'-GATCTGATGCTCAAGCTGGTAATCAGCCAC-3'); DAQD $^{486}$ backward (5'-GTGGCTGATTACCAGCTTGAGCATCAGATC-3'); DSKD ${ }^{502}$ forward (5'-GAAGACAGCAAAGCCAACCATGAAGCCAG-3'); DSKD 502 backward (5'-CTGGCTTCATGGTTGGCTTTGCTGTCTTC-3').
Site directed mutagenesis was also used to generate deletion mutants corresponding to caspase-generated fragments of LEDGF/ p75. For these experiments, the LEDGF/p75 cDNA cloned into in the pET28a-dfs70 plasmid was subcloned into a pcDNA3.1+ vector (Invitrogen) to generate a plasmid designated pcDNA-ledgf/p75. This plasmid was then used to create LEDGF/p75 mutants corresponding to the cleavage fragments. The constructs were made by sitedirected mutagenesis and PCR to generate plasmids designated pcDNA-ledgf/p754N (lacking residues 1-30), pcDNA-ledgf/p754C (lacking residues 487-530) and pcDNA-ledgf/p754NC (lacking residues 1-30 and 487-530). For the construction of pcDNAledgf/p75 $\Delta \mathrm{N}$, nucleotides coding for the $\mathrm{NH}_{2}$-terminus of LEDGF/p75 were deleted by site-directed mutagenesis (forward primer: $5^{\prime}$ GGAATTCGTTAACGCCACCATGGGAGC-3', backward primer: 5'GCTCCCATGGTGGCGTTAACGAATTCC-3'). A stop codon TAA was inserted by site-directed mutagenesis into pcDNA-ledgf/p75 to generate pcDNA-ledgf/p754C (forward primer, 5'-GGAGGATCTGATGCTCAAGATTAATCAGCCACAAC-3', backward primer, 5'GTTGTGGCTGATTAATCTTGAGCATCAGATCCTCC-3'). The later set of primers was used to generate pcDNA-ledgf/p75 $\triangle N C$ by inserting the stop codon into the pcDNA-ledgf/p75 $1 \mathrm{~N}$ plasmid. Details on the construction of these mutants are available upon request.

\section{In vitro cleavage of LEDGF/p75 by recombinant caspases}

LEDGF/p75 was synthesized in vitro using the TNT Coupled Reticulocyte Lysate System (Promega) and labeled with biotinylated lysine using the Transcend ${ }^{(i x}$ Non-Radioactive Translation Detection System (Promega), following the manufacturer's instruction. DNA templates used for in vitro transcription/translation (TNT) were pET28a-dfs70 and pcDNA-ledgf/p75. In the pET28a-dfs70 plasmid, the LEDGF/p75 sequence was fused to $T 7$ protein and $6 x$-histidine tags. Five $\mu \mathrm{l}$ aliquots of the in vitro translated LEDGF/p75 were incubated with different concentrations of recombinant caspases-3, -6 , $-7,-8$ and -9 (Pharmingen) in cleavage buffer (20 mM PIPES, pH 7.2, $100 \mathrm{mM} \mathrm{NaCl}, 1 \mathrm{mM}$ EDTA, $0.1 \%$ CHAPS, $10 \%$ sucrose, $100 \mathrm{mM}$ DTT) at $37^{\circ} \mathrm{C}$ for $90-120 \mathrm{~min}$. An equal volume of SDS-PAGE sample buffer was added after incubation followed by heating at $95^{\circ} \mathrm{C}$ for $5 \mathrm{~min}$. Protein samples were subjected to SDS-PAGE and transferred to nitrocellulose membranes. In vitro translated proteins, labeled with biotinylated lysine, were detected by chemiluminescence (NEN Life Science).

\section{Transfection experiments}

For expression of LEDGF/p75 and its mutants in mammalian cells, we transfected human HepG2 cells with plasmids pcDNA-ledgf/p75,

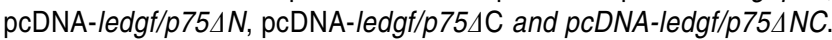
Expression of LEDGF/p75 and its mutants was under the control of CMV promoter. HepG2 cells $\left(1 \times 10^{6}\right.$ cells per $60 \mathrm{~mm}$ dish) were transfected with $1 \mu \mathrm{g}$ of the above constructs using Effectene (Qiagen Inc.). Transfected HepG2 cells were grown in Dulbecco s Modified Eagle Medium (DMEM) containing $600 \mu \mathrm{g} / \mathrm{ml}$ of G418 (Fisher Biotech) for up to 30 days to generate stably transfected cell clones. HepG2 clones were obtained stably expressing full-length/wild-type LEDGF/ p75 (HepG2-LEDGF/p75WT) and two deletion mutants (HepG2LEDGF/p75 $\Delta$ NC and HepG2-LEDGF/p75 $\Delta$ C). Cells transfected with pcDNA3.1+ vector alone, used as control, were designated HepG2Vec. 


\section{Cell survival and proliferation assays}

The ability of LEDGF/p75 and its mutants to promote cell survival and proliferation was evaluated using the colorimetric WST-1 assay (Roche Molecular Biochemicals) for the quantification of cell survival, cytotoxicity, and proliferation. ${ }^{54}$ This assay is based on the reduction of the tetrazolium salt WST-1 (4-[3-(4-iodophenyl)-2-(4-nitrophenyl)2H-5-tetrazolio]-1,3-benzene di-sulfonate) by mitochondrial dehydrogenases in viable cells. Upon reduction, WST-1 forms a watersoluble formazan. For cell survival assays, stable HepG2 clones were grown at a density of $1.5 \times 10^{4}$ cells/well in 96-well microtiter plates and maintained overnight in DMEM containing 10\% fetal bovine serum (FBS). Cells were then washed twice with PBS and transferred to FBS-free DMEM. Ten $\mu \mathrm{l}$ of WST-1 were added to the medium at 0, 24, 48, 72 and $96 \mathrm{~h}$. Plates were incubated for $2 \mathrm{~h}$ at $37^{\circ} \mathrm{C}$ and analyzed for absorbance at $\mathrm{A}_{450}-\mathrm{A}_{630}$. The absorbance of complete DMEM without cells was used as blank. Experiments were repeated at least three times in triplicates. For proliferation assays, cells were grown at a density of $1.0 \times 10^{4}$ cells/well in 96well microtiter plates and maintained overnight in DMEM containing $10 \%$ FBS. WST-1 was then added to the medium at 0,24 and $48 \mathrm{~h}$. Absorbance was measured at $A_{450}-A_{630}$.

\section{Bioinformatics tools}

LEDGF/p75protein sequence was searched against the Protein Domain database (ProDom; http://protein.toulouse.inra.fr/prodom.html) to identify the presence of any known motifs or domains. A search of the non-redundant protein database with Position Specific Iterated-Basic Local Alignment Search Tool (PSI-BLAST), available at http://www.ncbi.nlm.nih.gov/BLAST, was conducted to identify proteins with statistically significant similarity to potential domains within LEDGF/p75. Multiple sequence alignments were performed using CLUSTAL X, available at http://ftp-igbmc.u-strasbg.fr/pub/Clustal X Comparison of LEDGF/p75 sequence with complete and unfinished genomes of mammalian species was performed at http://www.tigr.org. Identification of an AT-hook element in the LEDGF/p75 sequence was done at http://www.blocks.fhcrc.org. Prediction of secondary structure of the LEDGF/p75 HATH/PWWP domain was obtained using the PSIPRED and PHDsec programs, available at http://bioinf.cs.ucl.ac.uk/psiform.html and http://cubic.bioc.columbia.edu/predictprotein, respectively.

\section{Acknowledgements}

We are grateful to Drs Eng M Tan and Edward Chan (The Scripps Research Institute, La Jolla, CA, USA) and Dr Robert L Ochs (Precision Therapeutics, Pittsburgh, PA, USA) for valuable suggestions and discussions, for the kind gift of autoantibodies to LEDGF/p75, and for the pET28a-dfs70 plasmid. We also thank Drs Mark Johnson and Qinhong Ma (Loma Linda University) for valuable suggestions and discussions on sequence analysis, and Drs Marina Zemskova and Maria Filippova (Loma Linda University) for technical assistance. Support for microscopy and imaging facilities was provided by the Hedco Foundation. This work was supported by the National Institutes of Health Grant Al44088 to CA Casiano and by a Basic Science Research Grant from Loma Linda University School of Medicine.

\section{References}

1. Leung DY (2000) Atopic dermatitis: new insights and opportunities for therapeutic intervention. J. Allergy Clin. Immunol. 105: 860-876

2. Halbert AR, Weston WL and Morelli JG (1995) Atopic dermatitis: is it an allergic disease? J. Am. Acad. Dermatol. 33: 1008-1018

3. Akdis CA, Akdis M, Trautmann A and Blaser K (2000) Immune regulation in atopic dermatitis. Curr. Opin. Immunol. 12: 641-646

4. Ochs RL, Muro Y, Si Y, Ge H, Chan EK and Tan EM (2000) Autoantibodies to DFS70 kd/transcription coactivator p75 in atopic dermatitis and other conditions. J. Allergy Clin. Immunol. 105: 1211-1220

5. Muro Y (2001) Autoantibodies in atopic dermatitis. J. Dermatol. Sci. 25: 171-178

6. Valenta R, Seiberler S, Natter S, Mahler V, Mossabeb R, Ring J and Stingl G (2000) Autoallergy: a pathogenetic factor in atopic dermatitis? J. Allergy Clin. Immunol. 105: 432-437

7. Ohkouchi K, Mizutani H, Tanaka M, Takahashi M, Nakashima K and Shimizu M (1999) Anti-elongation factor-1alpha autoantibody in adult atopic dermatitis patients. Int. Immunol. 11: 1635-1640

8. Seiberler S, Bugajska-Schretter A, Hufnagl P, Binder BR, Stockl J, Spitzauer S, Valent $P$ and Valenta $R$ (1999) Characterization of IgE-reactive autoantigens in atopic dermatitis. 1. Subcellular distribution and tissue-specific expression. Int. Arch. Allergy Immunol. 120: 108-116

9. Seiberler S, Natter S, Hufnagl P, Binder BR and Valenta R (1999) Characterization of IgE-reactive autoantigens in atopic dermatitis. 2. A pilot study on $\lg \mathrm{E}$ versus IgG subclass response and seasonal variation of $\lg \mathrm{E}$ autoreactivity. Int. Arch. Allergy Immunol. 120: 117-125

10. Valenta R, Maurer D, Steiner R, Seiberler S, Sperr WR, Valent P, Spitzauer S, Kapiotis S, Smolen J and Stingl G (1996) Immunoglobulin E response to human proteins in atopic patients. J. Invest. Dermatol. 107: 203-208

11. Ge H, Si Y and Roeder RG (1998) Isolation of cDNAs encoding novel transcription coactivators p52 and p75 reveals an alternate regulatory mechanism of transcriptional activation. EMBO J. 17: 6723-6729

12. Singh DP, Ohguro N, Chylack Jr LT and Shinohara T (1999) Lens epitheliumderived growth factor: increased resistance to thermal and oxidative stresses. Invest. Ophthalmol. Vis. Sci. 40: 1444-1451

13. Yamada K, Senju S, Shinohara T, Nakatsura T, Murata Y, Ishihara M, Nakamura S, Ohno S, Negi A and Nishimura Y (2001) Humoral immune response directed against LEDGF in patients with VKH. Immunol. Lett. 78: 161-168

14. Singh DP, Ohguro N, Kikuchi T, Sueno T, Reddy VN, Yuge K, Chylack Jr LT and Shinohara T (2000) Lens epithelium-derived growth factor: effects on growth and survival of lens epithelial cells, keratinocytes, and fibroblasts. Biochem. Biophys. Res. Commun. 267: 373-381

15. Singh DP, Fatma N, Kimura A, Chylack Jr LT and Shinohara T (2001) LEDGF binds to heat shock and stress-related element to activate the expression of stress-related genes. Biochem. Biophys. Res. Commun. 283: 943-955

16. Matsui H, Lin LR, Singh DP, Shinohara T and Reddy VN (2001) Lens epitheliumderived growth factor: increased survival and decreased DNA breakage of human RPE cells induced by oxidative stress. Invest. Ophthalmol. Vis. Sci. 42: 2935-2941

17. Fatma N, Singh DP, Shinohara T and Chylack Jr LT (2001) Transcriptional regulation of the AOP2 gene, a thiol-specific antioxidant, by LEDGF to protect cells from oxidative stress. J. Bio. Chem. 276: 48899-48907

18. Ahuja P, Caffe AR, Holmqvist I, Soderpalm AK, Singh DP, Shinohara T and van Veen T (2001) Lens epithelium-derived growth factor (LEDGF) delays photoreceptor degeneration in explants of $\mathrm{rd} / \mathrm{rd}$ mouse retina. Neuroreport. 12: $2951-2955$

19. Nishizawa Y, Usukura J, SinghDP, Chylack JrLT and Shinohara T (2001) Spatial and temporal dynamics of two alternatively spliced regulatory factors, lens epithelium-derived growth factor (ledgf/p75) and p52, in the nucleus. Cell Tissue Res. 305: 107-114

20. Machida S, Chaudhry P, Shinohara T, Singh DP, Reddy VN, Chylack Jr LT, Sieving PA and Bush RA (2001) Lens epithelium-derived growth factor promotes photoreceptor survival in light-damaged and RCS rats. Invest. Ophthalmol. Vis. Sci. 42: 1087-1095

21. Nakamura M, Singh DP, Kubo E, Chylack Jr LT and Shinohara T (2000) LEDGF: survival of embryonic chick retinal photoreceptor cells. Invest. Ophthalmol. Vis. Sci. 41 : $1168-1175$ 
22. Sharma P, Singh DP, Fatma N, Chylack Jr LT and Shinohara T (2000) Activation of LEDGF gene by thermal-and oxidative-stresses. Biochem. Biophys. Res. Commun. 276: $1320-1324$

23. Trautmann A, Akdis M, Klunker S, Blaser K and Akdis CA (2001) Role of apoptosis in atopic dermatitis. Int. Arch. Allergy Immunol. 124: 230-232

24. Akdis M, Trautmann A, Klunker S, Blaser K and Akdis CA (2001) Cytokine network and dysregulated apoptosis in atopic dermatitis. Acta Odontol. Scand. 59: $178-182$

25. Trautmann A, Akdis M, Kleemann D, Altznauer F, Simon HU, Graeve T, Noll M, Brocker EB, Blaser K and Akdis CA (2000) T cell-mediated Fas-induced keratinocyte apoptosis plays a key pathogenetic role in eczematous dermatitis. J. Clin. Invest. 106: 25-35

26. Casiano CA, Martin SJ, Green DR and Tan EM (1996) Selective cleavage of nuclear autoantigens during CD95 (Fas/APO-1)- mediated T cell apoptosis. J. Exp. Med. 184: 765-770

27. Casiano CA, Ochs RL and Tan EM (1998) Distinct cleavage products of nuclear proteins in apoptosis and necrosis revealed by autoantibody probes. Cell Death. Differ. 5: $183-190$

28. Wu X, Molinaro C, Johnson N and Casiano CA (2001) Secondary necrosis is a source of proteolytically modified forms of specific intracellular autoantigens: implications for autoimmunity. Arthritis Rheum. 44: 2642-2652

29. Casciola-Rosen LA, Anhalt G and Rosen A (1995) DNA-dependent protein kinase is one of a subset of autoantigens specifically cleaved early during apoptosis. J. Exp. Med. 182: 1625-1634

30. Casciola-Rosen L, Andrade F, Ulanet D, Wong WB and Rosen A (1999) Cleavage by granzyme $B$ is strongly predictive of autoantigen status: implications for initiation of autoimmunity. J. Exp. Med. 190: 815-826

31. Rosen A and Casciola-Rosen L (1999) Autoantigens as substrates for apoptotic proteases: implications for the pathogenesis of systemic autoimmune disease. Cell Death Differ. 6: 6-12

32. Utz PJ and Anderson P (1998) Posttranslational protein modifications, apoptosis, and the bypass of tolerance to autoantigens. Arthritis Rheum. 41: $1152-1160$

33. Rovere P, Sabbadini MG, Fazzini F, Bondanza A, Zimmermann VS, Rugarli $C$ and Manfredi AA (2000) Remnants of suicidal cells fostering systemic autoaggression. Apoptosis in the origin and maintenance of autoimmunity. Arthritis Rheum. 43: 1663-1672

34. Rodenburg RJ, Raats JM, Pruijn GJ and van Venrooij WJ (2000) Cell death: a trigger of autoimmunity? Bioessays 22: 627-636

35. Adrain C and Martin SJ (2001) The mitochondrial apoptosome: a killer unleashed by the cytochrome seas. Trends Biochem. Sci. 26: 390-397

36. Chang HY and Yang X (2000) Proteases for cell suicide: functions and regulation of caspases. Microbiol. Mol. Biol. Rev. 64: 821-846

37. Earnshaw WC, Martins LM and Kaufmann SH (1999) Mammalian caspases: structure, activation, substrates, and functions during apoptosis. Annu. Rev. Biochem. 68: 383-424

38. Cohen GM (1997) Caspases: the executioners of apoptosis. Biochem. J. 326: $1-16$
39. Flygare J, Hellgren D and Wennborg A (2000) Caspase-3 mediated cleavage of HsRad51 at an unconventional site. Eur. J. Biochem. 267: 5977-5982

40. Samejima K, Svingen PA, Basi GS, Kottke T, MesnerJrPW, StewartL, Durrieu F, Poirier GG, Alnemri ES, Champoux JJ, Kaufmann SH and Earnshaw WC (1999) Caspase-mediated cleavage of DNA topoisomerase I at unconventional sites during apoptosis. J. Biol. Chem. 274: 4335-4340

41. Stec I, Nagl SB, van Ommen GJ and den Dunnen JT (2000) The PWWP domain: a potential protein-protein interaction domain in nuclear proteins influencing differentiation? FEBS Lett. 473: 1-5

42. Singh DP, Kimura A, Chylack Jr LT and Shinohara T (2000) Lens epitheliumderived growth factor (LEDGF/p75) and p52 are derived from a single gene by alternative splicing. Gene 242: 265-273

43. Emoto Y, Manome Y, Meinhardt G, KisakiH, Kharbanda S, Robertson M, Ghayu T, Wong WW, Kamen R, Weichselbaum R and Kufe D (1995) Proteolytic activation of protein kinase $\mathrm{C}$ delta by an ICE-like protease in apoptotic cells. EMBO J. 14:6148-6156

44. Cheng EH, Kirsch DG, Clem RJ, Ravi R, Kastan MB, Bedi A, Ueno K and Hardwick JM (1997) Conversion of Bcl-2 to a Bax-like death effector by caspases. Science 278: 1966-1968

45. Fujita N, Nagahashi A, Nagashima K, Rokudai S and Tsuruo T (1998) Acceleration of apoptotic cell death after the cleavage of Bcl-XL protein by caspase-3-like proteases. Oncogene 17: 1295-1304

46. Rokudai S, Fujita N, Hashimoto Y and Tsuruo T (2000) Cleavage and inactivation of antiapoptotic Akt/PKB by caspases during apoptosis. J Cell Physiol. 182 $290-296$

47. Reeves R (2001) Molecular biology of HMGA proteins; hubs of nuclear function Gene 277: 63-81

48. Kalden JR (1997) Defective phagocytosis of apoptotic cells: possible explanation for the induction of autoantibodies in SLE. Lupus 6: 326-327

49. Rosen A and Casciola-Rosen L (2001) Clearing the way to mechanisms of autoimmunity. Nat. Med. 7: 664-665

50. Savill J and Fadok V (2000) Corpse clearance defines the meaning of cell death Nature 407: 784-788

51. Green DR and HM Beere (2000) Apoptosis. Gone but not forgotten. Nature 405 $28-29$

52. Casiano CA, Wu Xand CMolinaro (2000) Apoptosis, necrosis, and the genesis of antinuclear autoantibodies: an integrated view. In Autoantigens and Autoantibodies: Diagnostic Tools and Clues to Understanding Autoimmunity, Conrad Kand Tan EM, eds (Lengerich, Germany: PABST Science Publishers) pp. 152186

53. Ayaki M, Sueno T, Singh DP, ChylackJrLT and Shinohara T (1999) Antibodies to lens epithelium-derived growth factor (LEDGF) kill epithelial cells of whole lenses in organ culture. Exp. Eye Res. 69: 139-142

54. Matsumura $\mathrm{H}$, Shimizu $\mathrm{Y}$, Ohsawa $\mathrm{Y}$, Kawahara A, Uchiyama $\mathrm{Y}$ and Nagata $\mathrm{S}$ (2000) Necrotic death pathway in Fas receptor signaling. J Cell Biol. 151: 1247 1256 